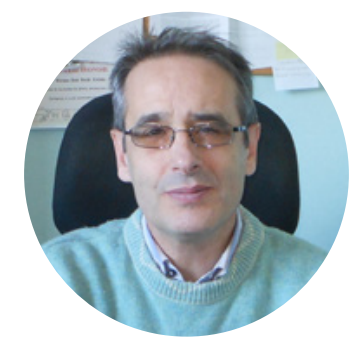

Enrique Roche

Profesor del Área de Nutrición y

Bromatología de la UMH

\title{
Gymsen: \\ Gimnasia Sensorial para Mayores
}

Alicia de Lara

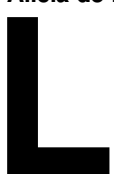

os sentidos del gusto y el olfato son los encargados de diferenciar el sabor de los alimentos. Mientras la lengua proporciona la percepción del dulce, salado, amargo y ácido, el olfato aporta el resto de los matices. No obstante, cuando se alcanza la vejez, estas habilidades sensoriales pierden facultades. Como ocurre con el oído o la visión, también el gusto se deteriora en cierta manera, lo que implica que algunas personas mayores pierdan el interés por la comida y no sientan satisfacción al ingerir determinados alimentos. Algo que puede traducirse en malnutrición, bajada de defensas y deficiencia funcional. De hecho, muchas enfermedades relacionadas con la edad son causa de una mala alimentación.

Descubrir a las personas mayores nuevos sabores que puedan introducir en su dieta para hacerla más sana y equilibrada, a la vez que más atractiva para sus sentidos, es el objetivo del proyecto 'Gymsen: Gimnasia Sensorial para Mayores', liderado por el profesor del Área de Nutrición y Bromatología de la Universidad Miguel Hernández (UMH) de Elche Enrique Roche. La iniciativa pretende, a través de talleres de estimulación sensorial, que los mayores recuperen el interés por la comida para reducir el riesgo de enfermedades, a la vez que promover una alimentación saludable.

En Gymsen colaboran asociaciones de diferentes países: la ONG italiana Anziani e non solo y la Agencia Europea para el Desarrollo en la República Checa, que trabajan para mejorar la calidad de vida de las personas mayores; el instituto téc- nico sueco Science Partner junto con el Instituto Tecnológico AINIA (Valencia), encargados de la parte técnica en las actividades de estimulación sensorial y la Asociación de Enfermos de Alzheimer y Trastornos Relacionados en Atenas. Desde la UMH, se ha gestionado la participación en el proyecto de ancianos intelectualmente activos e independientes a través del programa de la UMH AUNEX, en el que personas mayores de 55 años asisten a clases, actividades y cursos organizados por la Universidad; uno de ellos relacionado con la nutrición. La también profesora de Nutrición y Bromatología de la UMH Marta Beltrá aborda durante las sesiones cuestiones relacionadas con mitos y errores en la nutrición y sobre los beneficios de la dieta Mediterránea.

Antes de poner en marcha los talleres, los socios concluyeron los gustos, texturas y sabores que condicionan la nutrición de las personas mayores y que eran comunes a los diferentes países implicados en el proyecto. Los resultados sirvieron para establecer una base de tomate (para los sabores salados) y otra de manzana (para los dulces). Después de varios encuentros y de la aproximación a los hábitos alimenticios de los participantes, los investigadores definieron la estructura de los talleres y procedieron a ejecutarlos en sus respectivos grupos de actuación.

En los talleres de gimnasia sensorial que comenzaron en la sede de las AUNEX de Torrevieja el pasado mes de mayo, se realizaron diversas actividades, como distinguir los olores de las diferentes especias y condimentos e identificar, median- 


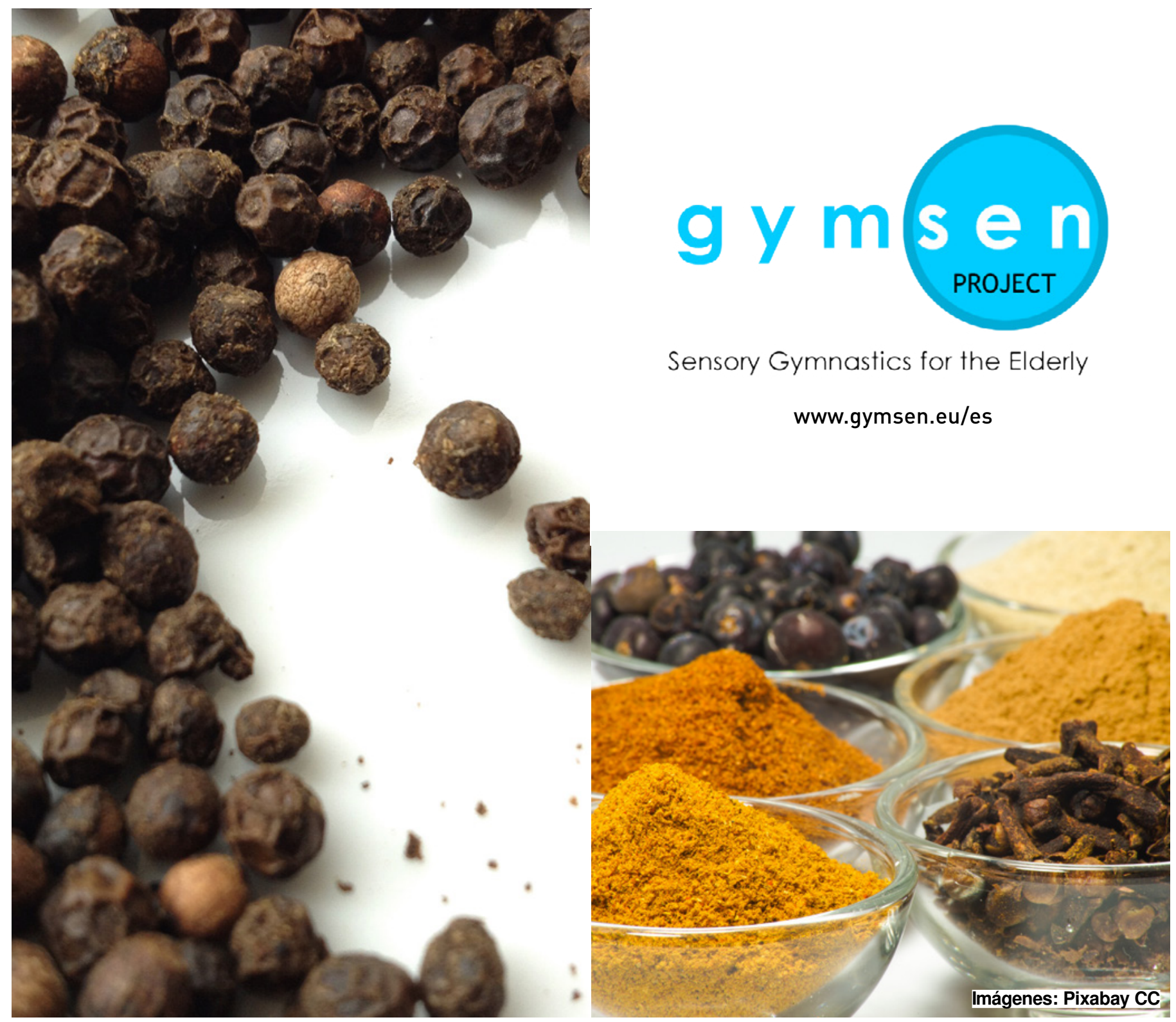

te la cata, los ingredientes añadidos en las recetas de tomate y en las mezclas de zumo de manzana, entre otros. Las actividades fueron aumentando en dificultad a la hora de diferenciar las sustancias y los olores, por ejemplo, la presencia de sal, ajo, paprica o limón.

Según explica el profesor Roche, el grupo de Torrevieja presentó una gran predisposición y, a falta del análisis de los resultados, los participantes demostraron que sus sentidos del gusto y del olfato estaban en buena forma. "Durante el taller, he descubierto nuevas especias que podré aplicar en mis guisos. De hecho, ha sido todo un reto averiguar qué sabores se correspondían a cada una de las muestras e, incluso, hay alguno que no he logrado adivinar", señaló durante la actividad Carmen Romero, una de las participantes, de 84 años.

Gymsen es una investigación pionera en Europa que se engloba dentro de las acciones de cooperación para la innovación de intercambio de buenas prácticas del programa Erasmust. Los resultados de los distintos talleres se estudiarán durante el verano de 2016,

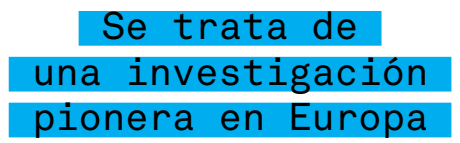

se publicarán en septiembre $y$, según Enrique Roche, se espera que la investigación se convierta en una herramienta eficaz para reforzar la nutrición en los mayores. Tal y como afirma el profesor, el acto de comer, además de propiciar un ambiente reparador y reponedor del gasto energético diario, también supone un estímulo sensorial muy importante para la vida de los mayores. 